\title{
Committing to Change: A Persuasive Systems Design Analysis of User Commitments for a Behaviour Change Support System
}

\section{Michael Oduor and Harri Oinas-Kukkonen}

Oulu Advanced Research on Services and Information Systems, Faculty of Information Technology and Electrical Engineering, University of Oulu, Oulu, Finland

\{michael.oduor**, harri.oinas-kukkonen\}@ oulu.fi

** Corresponding author 


\title{
Committing to Change: A Persuasive Systems Design Analysis of User Commitments for a Behaviour Change Support System
}

\author{
Abstract \\ Persuasive systems in different domains have been used to support people in changing their \\ behaviours. These systems motivate desirable behaviour in users by providing relevant \\ information, tracking user progress, and giving them feedback. This study investigates the \\ persuasive features of a web-based information system that supports the enforcement of \\ user commitments. A structural equation modelling approach and analysis of open text \\ responses are used to identify the factors that affect the intention to continue to use the \\ system, to gather users' perspectives on how the system helps them to stick to their goals \\ and the improvements that could be made. Data $(N=227)$ collected from the system's \\ users is tested against the proposed research model. The results show that $30 \%$ of users' \\ continuance intention is explained by the implemented persuasive software feature \\ categories (computer-human dialogue support, primary task support, perceived credibility, \\ and social support) and perceived competence. Of these categories, primary task support \\ has the strongest effect on perceived competence and continuance intention. The results \\ also reveal how the system helps users to be consistent in their goals and the lack of \\ specialized social support features. The study concludes with a discussion and \\ recommendations for future research.
}

Keywords: persuasive systems design; behaviour change; commitment; continuance intention; perceived competence

\section{Introduction}

Technological changes have impacted the ways in which we communicate, and recent years have seen a growth in systems aimed at behaviour change. Technology, although often seen as a tool to accomplish goals, is never neutral, and people are constantly being influenced whether intentionally or as an unintentional side effect of the design (Oinas-Kukkonen, 2013). As Kranzberg states (1986 p. 545), “Technology is neither good nor bad; nor is it neutral ... technology's interaction with the social ecology is such that technical developments 
frequently have environmental, social, and human consequences that go far beyond the immediate purposes of the technical devices and practices themselves".

The design of information systems to positively influence user behaviour is nowadays prevalent and research, for example Kelders et al. 2012, has pointed to the importance of persuasive systems design. Although, there isn't yet a common understanding when or how persuasive strategies work and why certain strategies might only work in some cases (Schneider, Moser, Butz, \& Alt, 2016). Furthermore, a comprehensive system that meets every individuals' needs has yet to be developed and no single solution can solve all our problems (Drozd, Lehto, \& Oinas-Kukkonen, 2012). Therefore, an important consideration for systems supporting behaviour change, or Behaviour Change Support Systems (BCSSs), is the deliberate attempt to cause a cognitive and/or emotional change in the user by helping to transform their current state into another planned state leading to a change in their behaviour (Oinas-Kukkonen, 2013).

This is usually approached by persuasive systems design (Oinas-Kukkonen \& Harjumaa, 2009; Schneider et al., 2016) which aims to maintain high levels of user engagement and motivation because persuasive communication is more likely to be effective to the extent that the reason for holding the position outlined in the appeal matches the recipients dispositions (Wood, 2000). For example, Kelders et al. (2012) found that persuasive systems design, particularly dialogue support features which facilitate interaction between the user and the system, influences adherence to web-based intervention programs. Chatterjee \& Price (2009) further add that interpersonal interactions with technology are essential for persuading users to adopt the desired behaviour.

The conceptualization of BCSS was introduced as an object of persuasive systems and defined as "A sociotechnical information system with psychological and behavioural outcomes 
designed to form, alter or reinforce attitudes, behaviours or an act of complying without using coercion or deception" (Oinas-Kukkonen, 2013). BCSSs are inherently transformative and highlight voluntary approaches in which people use technology to change their own behaviours by relying upon their personal motivation or goals (Oinas-Kukkonen, 2013). These systems and technology, in general, are more effective in persuasion and offer a potential path to long-term behaviour change as they leverage technology's capabilities (Fogg, 2003) to influence users. As the role of technology increases in people's day-to-day activities and decision making, new opportunities to assist people in making self-beneficial choices have arisen through, for example, the use of persuasive systems to digitally present choices in a way that leverages people's decision-making processes, thus encouraging them to make self-beneficial decisions (Lee et al. 2011).

Understanding users' relationship with persuasive systems, the dynamics of that relationship, and users' perceptions of these systems is essential to understanding their decision to continue using them (Al-Natour \& Benbasat, 2009). There has also been limited research on the efficacy of persuasive software features and how these features affect the continued use of BCSS (Lehto \& Oinas-Kukkonen, 2015). Therefore, the present study aims to address this research gap by investigating users' perceptions of a web-based system for commitment. A selfcommitment system that helps users to make self-beneficial decisions that limit future counterproductive behaviour (Bryan, Karlan, \& Nelson, 2010).

Specifically, the study examines the effect of the Persuasive Systems Design (PSD) model's features (Oinas-Kukkonen \& Harjumaa, 2009) on users' perceived competence and how this, in turn, predicts their intention to continue using the system. The study outlines (see study design section) the persuasion context for the system which describes the persuasive 
characteristics of the system and then outlines the persuasive constructs formulating the hypotheses. Data $(N=227)$ collected from the system's users in two stages is tested against the proposed research model using partial least squares (PLS), a structural equation modelling (SEM) approach. By applying the PSD model, it is possible to systematically investigate how persuasive software features are used and evaluate their influence. This quantitative part is supplemented by a review of users' open text responses to questions asking the services or features that the system could offer that would add significant value to their use and how the commitment feature of the system and the consequence (being charged for derailing on a goal) helps users to meet their goals. Results show that primary task support from the PSD model's software feature categories is a strong predictor of users' perceived competence and continuance intention.

The rest of the paper is organized as follows. First, we present the theoretical background, the research model and hypotheses. Second, we discuss the research methodology. Third, the results of the analysis are presented. Fourth, we discuss the results, implications and limitations, and end with the conclusion.

\section{Theoretical Background}

\section{Persuasive Systems}

Recent years have seen an increase in information systems aimed at motivating users to meet their goals by guiding them through a process of changing their attitudes and behaviour (OinasKukkonen \& Harjumaa, 2009; Chatterjee \& Price, 2009). Persuasion as a consideration for information technology is often concerned with how behaviour change can be enabled by intervening in moments of local decision making and by acknowledging, rewarding and 
enhancing motivation for desirable behaviours (Dourish, 2010). Persuasion is a situation whereby a recipient receives an intervention (e.g., a persuasive message) that refers to something outside the message itself (the context) (Briñol \& Petty, 2009). Persuasion techniques are most effective when they are interactive and when persuaders adjust their influencing tactics as the situation evolves (Fogg, 2003).

Persuasive systems aim to persuade users to choose a particular course of action and are designed with the intent to serve some overall good (Benbasat, 2010). They combine context and cognition, external factors and the individual, as well as considering personal factors such as motivation alongside environmental ones such as triggers (Lockton, 2012). Therefore, it is important for both software developers and the general audience to be aware of the various ways of and the approaches to how people may be, are being, and will be influenced through the design of computerized systems (Oinas-Kukkonen, 2013).

Oinas-Kukkonen and Harjumaa (2009) describe persuasive systems as 'systems designed to reinforce, change or shape attitudes or behaviours without using coercion or deception'. Persuasive systems are developed based on theories on human behaviour and have the aim to influence behaviours in a desirable way (Fogg, 2003). From a user's perspective, computers can operate as tools that increase capability, as mediums that provide interactive experiences, and as social actors that create and enhance relationships (Fogg, 2003). Technology does not, in itself, seek to influence, but, through services that can be built on top of the technology, it facilitates behaviour change (Lockton, 2012). Within persuasive systems, the standard approach is to design systems that try to motivate users to behave in a more desirable way by providing information or giving them feedback (Brynjarsdottir et al., 2012; DiSalvo et al., 2010; Lee, Kiesler, \& Forlizzi, 2011). 
As persuasive systems are nowadays employed in different domains, various strategies to motivate and enhance user experiences may be applied in their development to support different outcomes and behaviour change strategies (Berkovsky, Freyne, \& Oinas-Kukkonen, 2012). The underlying principle is to understand users and integrate this understanding into developing systems that help users to achieve specific objectives that could be health and well-being or lifestyle-related. This could be through design strategies that help people to change their everyday behaviours (Consolvo, McDonald, \& Landay, 2009), investigating how systems' perceived persuasiveness, and the design of persuasive features influence users' adoption, continuance intention, and adherence to these systems (Kelders et al., 2012; Lehto \& OinasKukkonen, 2015; Lehto, Oinas-Kukkonen, Pätiälä, \& Saarelma, 2012), or analysing the persuasive user experiences of a BCSS, for instance, for the prevention of metabolic syndrome (Karppinen et al., 2016). Other previous research includes, for example, analysing how the features implemented in a persuasive system are compatible with users' goals and affect system usage (Ebermann \& Brauer, 2016), exploring the need for and role of reflection in persuasive systems design (Halttu \& Oinas-Kukkonen, 2017), using persuasive principles to analyse carbon management systems (Corbett, 2013), and to study attitudes towards fire safety (Chittaro \& Zangrando, 2010) among many others.

The main idea is to motivate the desirable behaviour by leveraging different persuasive techniques that promote user engagement and interactivity and help users to meet their goals. Commitment techniques and systems, discussed in the following section, are based on a minimalist approach where targets are set in a personalised manner and people are guided to make self-beneficial decisions. 


\section{Commitment and behaviour change}

There are numerous examples of suboptimal health behaviour, for example, unwillingness to think about problems when risks are known or data are ambiguous, in which people do not follow through on their goals (Mogler et al., 2013). Unhealthy behaviours are also responsible for a large proportion of healthcare costs and poor health outcomes (Rogers, Milkman, \& Volpp, 2014). Therefore, people require systems that support self-commitment as research has demonstrated their effectiveness in helping people to commit to goals (Beshears, Choi, Laibson, Madrian, \& Sakong, 2011; Reeves, 2011; Rogers et al., 2014). As people often set goals with varying degrees of formality that in most cases they fail to meet, such systems can be used to, for example, help people purchase unhealthy food in small portions to reduce intake (see Table 1 for examples of techniques for commitment) (Rogers et al., 2014).

Systems that support/enforce commitment, create accountability for completing the goals that people commit to (Bryan et al., 2010). According to Munson et al. (2015), such techniques relate to restricting the occurrence of future behaviour with the awareness of what your preferences will be at the time the behaviour is to take place - a request in the present that a future request be denied.

There is a strategic interaction between the self who creates the commitment device and the future self who is influenced by it. Indeed, it involves a three-stage interaction among the selves at three different times: when one makes a commitment (time 1), when one chooses to engage in an activity such as deciding between walking and watching TV (time 2), and when rewards or punishments are meted out (time 3).

Table 1. Examples of techniques for commitment (adapted from Rogers et al., 2014).

\begin{tabular}{|l|l|l|}
\hline Strategy & Description & Health Goal \\
\hline
\end{tabular}




\begin{tabular}{|c|c|c|}
\hline $\begin{array}{l}\text { Put money in a } \\
\text { deposit contract }\end{array}$ & $\begin{array}{l}\text { Forfeit money by failure to achieve a goal by a } \\
\text { given date (e.g., losing five pounds within } 2 \\
\text { months) }\end{array}$ & Any \\
\hline $\begin{array}{l}\text { Engage in } \\
\text { temptation } \\
\text { bundling }\end{array}$ & $\begin{array}{l}\text { Restrict access to instantly gratifying } \\
\text { experiences (e.g., watching TV) only to } \\
\text { occasions when engaging in goal-consistent } \\
\text { behaviours (e.g., exercising). }\end{array}$ & Any \\
\hline $\begin{array}{l}\text { Purchase vices in } \\
\text { small packages }\end{array}$ & $\begin{array}{l}\text { Limit portion sizes for unhealthy items (e.g., } \\
\text { junk food, alcohol) }\end{array}$ & $\begin{array}{l}\text { Reduce } \\
\text { consumption }\end{array}$ \\
\hline $\begin{array}{l}\text { Order groceries } \\
\text { online }\end{array}$ & Avoid purchasing unhealthy foods on impulse & Improve diet \\
\hline $\begin{array}{l}\text { Check into } \\
\text { rehabilitation }\end{array}$ & $\begin{array}{l}\text { Ensure no access to addictive substances (e.g., } \\
\text { alcohol, drugs) until professionals deem a patient } \\
\text { ready }\end{array}$ & Treat \\
\hline $\begin{array}{l}\text { Purchase annual } \\
\text { gym membership }\end{array}$ & $\begin{array}{l}\text { Ensure future gym visits will not require out-of- } \\
\text { pocket payment }\end{array}$ & $\begin{array}{l}\text { Increase } \\
\text { exercise }\end{array}$ \\
\hline
\end{tabular}

In many cases, the factors leading to unhealthy behaviours are an integral part of people's lifestyles and this is where intervention programs should be targeted. However, radical and longterm change is difficult to implement and, often, almost impossible to sustain (Fletcher, Pine, \& Page, 2007). Many people intend to improve their health, well-being and other behaviours (exercise, maintain a diet, quit smoking) in the future, but when the time comes to act on their 
intentions, they do not (Rogers et al., 2014). People are often aware of the changes they need to make in their behaviour but usually have a problem following through on their intentions, primarily due to a lack of self-control or willpower which weakens the more it is called upon (Beshears et al., 2011; Fletcher et al., 2007; Reeves, 2011). That is to say, people intend to make choices that carefully consider short-term and long-term cost and benefits, "but at the decisionmaking moment, they place disproportionate weight on immediate costs and benefits" (Beshears et al., 2011).

Furthermore, some of the solutions people choose to help them change a behaviour or form habits are often easy and do not result in any significant change because they are not accompanied by hard commitments. A solution to this problem is the use of systems that support commitment: " $a$ way of changing one's incentives to make an otherwise empty threat or promise credible" (Reeves, 2011). This involves entering into an arrangement that restricts people's future choice set by making some choices more expensive or making a present intention for a future action more substantial (Bryan et al., 2010; Moraveji, Akasaka, Pea, \& Fogg, 2011).

As systems that support the enforcing of commitments also involve persuasive design to motivate users, it is essential to empirically analyse the persuasive elements in these systems. Thus, we propose an approach to investigate the effect of persuasive software features on users' intention to continue using such a Web-based information system.

\section{Study Design}

\section{The Persuasive Systems Design model}

The PSD model (Oinas-Kukkonen \& Harjumaa, 2009) is used as the main conceptual framework in the present study. The PSD model is meant to solve real-world problems in the design and 
development of persuasive systems. The model is an integrative framework linked to prior knowledge of social psychological theories and information systems (IS) development (OinasKukkonen \& Harjumaa, 2009). The model outlines the postulates (psychological principles) behind the design of persuasive systems, the importance of considering the context of use, and the specific features implemented in persuasive systems (Oinas-Kukkonen \& Harjumaa, 2009). These features are outlined in the next section below under research model and hypotheses.

The psychological principles describe the neutrality of technology, its accessibility and reach, ease of use, how people make and enforce commitments, users' attitudes and persuasion strategies, the sequential nature of persuasion, the ideal moments for initiating persuasive features and openness in the development of persuasive systems (Oinas-Kukkonen \& Harjumaa, 2009).

After acknowledging the persuasion postulates, the context for persuasion should be considered when developing persuasive systems (Oinas-Kukkonen \& Harjumaa, 2009). Persuasion context analysis calls for an understanding of what takes place in the information processing event. Namely, understanding the roles of persuader, persuadee, message, channel, and the wider context. A thorough analysis of the persuasion context helps to recognise inconsistencies in a user's thinking, to discern opportune and/or inopportune moments for delivering messages, and the strategies for effective persuasion. Therefore, a system based on an understanding of how users' process information and that supports the making of commitments is expected to motivate users to change their behaviour (Oinas-Kukkonen and Harjumaa, 2009). 
Persuasion context analysis includes the intent of persuasion, the persuasion event, and the strategies in use (Oinas-Kukkonen \& Harjumaa, 2009). A summary of the persuasion context for the system ${ }^{1}$ examined in the current study is presented in Table 2.

Table 2. Persuasion context analysis of Beeminder (based on Oinas-Kukkonen 2013 and Oinas-Kukkonen and Harjumaa 2009).

\begin{tabular}{|c|c|}
\hline \multicolumn{2}{|r|}{ The Intent } \\
\hline Persuader & $\begin{array}{l}\text { The system is autogenous as it enables users to pursue their own goals } \\
\text { without the need for external consultation. }\end{array}$ \\
\hline $\begin{array}{l}\text { Intended } \\
\text { Outcome/Change }\end{array}$ & $\begin{array}{l}\text { They system focuses on long-term altering and reinforcing of target } \\
\text { behaviour (A/R-Outcome, B-Change). }\end{array}$ \\
\hline Bias & $\begin{array}{l}\text { The system is based on human decision-making theories from } \\
\text { behavioural economics and game theory which explain why people } \\
\text { might not always follow through on their intentions. }\end{array}$ \\
\hline \multicolumn{2}{|r|}{ The Event } \\
\hline Use context & $\begin{array}{l}\text { The system is primarily used to track users' health, financial, learning, } \\
\text { and productivity goals. There are common features available to all } \\
\text { users and those on premium plans get additional features. }\end{array}$ \\
\hline User context & $\begin{array}{l}\text { Users are encouraged to set their goals at realistic levels. They can } \\
\text { freely choose a goal, define the parameters for tracking the goal, and } \\
\text { progress at their own pace as long as they do not derail. }\end{array}$ \\
\hline
\end{tabular}

\footnotetext{
${ }^{1}$ www.beeminder.com
} 


\begin{tabular}{|c|c|}
\hline $\begin{array}{l}\text { Technology } \\
\text { context }\end{array}$ & $\begin{array}{l}\text { The system is designed according to current web standards and is } \\
\text { freely available to all users. Some advanced features require premium } \\
\text { plans. The system is accessible through the Web and as a native } \\
\text { mobile application for Android and iOS devices. }\end{array}$ \\
\hline \multicolumn{2}{|r|}{ The Strategy } \\
\hline Message & $\begin{array}{l}\text { The system helps users to either form new habits or to become } \\
\text { proficient by encouraging incremental goal setting and consistency in } \\
\text { maintaining the desired habits. The system is based on an } \\
\text { understanding of human decision-making principles. }\end{array}$ \\
\hline Route & $\begin{array}{l}\text { The system primarily relies on an indirect route to persuade the user } \\
\text { by plotting user progress that the user can easily access without the } \\
\text { need for further action. In the premium plans, there is also a direct } \\
\text { route where users are required to evaluate the persuasive message and } \\
\text { they also receive real-time support. }\end{array}$ \\
\hline
\end{tabular}

\section{Research model and hypotheses}

The design of persuasive systems is often user-centred and involves developing systems that meet the users' primary goal(s), facilitate interaction, are credible, and provide opportunities for social interaction (Oinas-Kukkonen \& Harjumaa, 2009). In addition to these persuasive features, this study investigates the effect of perceived competence (Ryan \& Deci, 2000; Williams, Freedman, \& Deci, 1998) on continuance intention (Bhattacherjee, 2001; Lehto \& OinasKukkonen, 2015).

The six constructs measured in the study are the persuasive features of dialogue support, primary task support, social support, credibility support, and two additional constructs on 
perceived competence and continuance intention. The constructs were measured using Likert scale items (ranging from strongly disagree to strongly agree) drawn from validated measures in IS and persuasive systems research.

The measurement items for the constructs can be found in the Appendix. Figure 1 presents the research model.

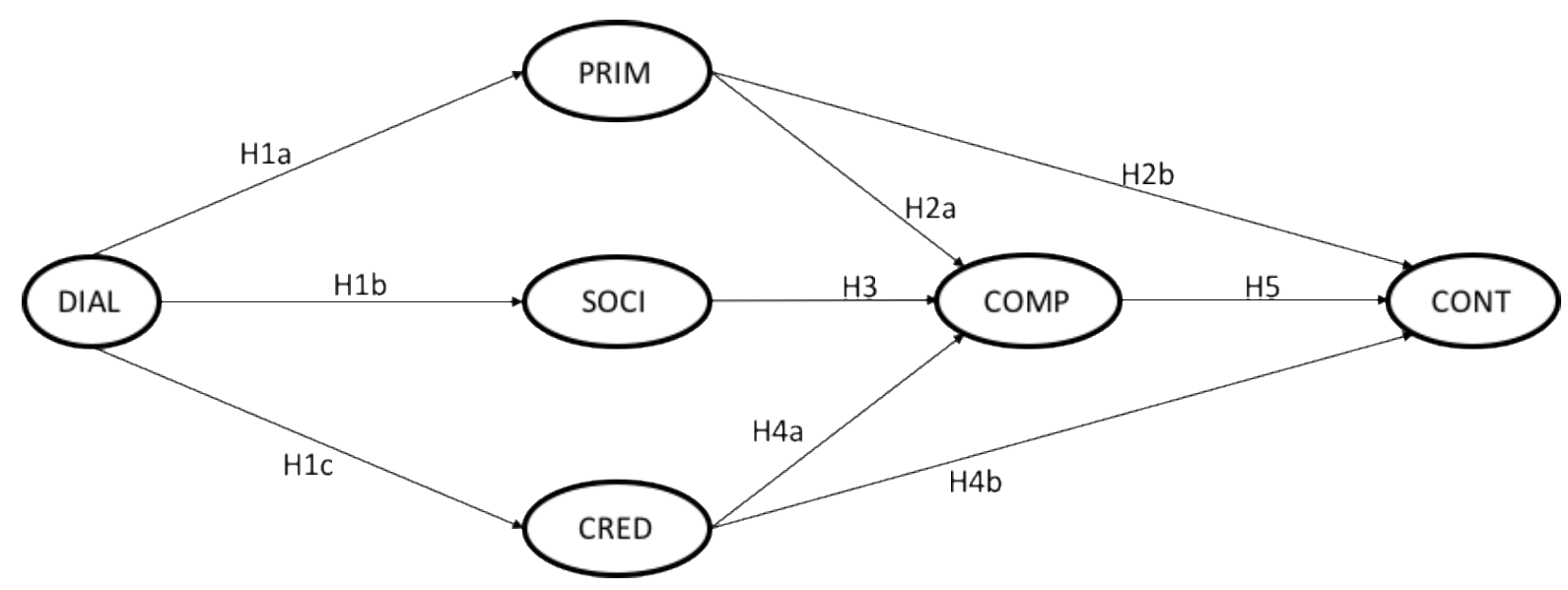

DIAL $=$ Dialogue support; PRIM = Primary task support; $\mathrm{SOCI}=$ Social support CRED = Perceived credibility $; \mathrm{COMP}=$ Perceived competence $; \mathrm{CONT}=$ Continuance intention.

Figure 1. Research Model

\section{Computer-human dialogue support}

Computer-human dialogue support (henceforth, dialogue support) features facilitate and improve communication between a system and its users, especially in terms of feedback for better guiding users toward their intended goals (Langrial, Lehto, Oinas-Kukkonen, Harjumaa, \& Karppinen, 2012; Lehto \& Oinas-Kukkonen, 2011). Reminding users of their target behaviour, for example, will more likely lead to goal achievement, and reminders in various forms (Ritterband, Thorndike, Cox, Kovatchev, \& Gonder-Frederick, 2009), such as automated and personalized emails and phone calls triggered by technology or a clinician, have been shown to help in task completion (Chiu et al., 2009; Langrial, Oinas-Kukkonen, Lappalainen, \& Lappalainen, 2013). 
Thus, these features are strongly linked to primary task support. Individuals' interactions with computers are also fundamentally social and from a user's perspective, computers can, in addition to being tools and mediums that increase capability and provide interactive experiences, be social actors that create and enhance relationships (Fogg, 2003; Nass \& Moon, 2000). Dialogue support also affects users' positive feelings toward the system, which likely influences the individuals' confidence (credibility) (Lehto et al., 2012). Therefore, we propose the following hypotheses:

H1a: Dialogue support positively affects primary task support.

H1b: Dialogue support positively affects social support.

H1c: Dialogue support positively affects perceived credibility.

\section{Primary task support}

Primary task support refers to the way in which a system helps users carry out their primary task (that is, the real-world activity that they would like to complete) (Oinas-Kukkonen \& Harjumaa, 2009). Primary task support aims to enhance users' self-efficacy and reduce the cognitive burden associated with using information systems by providing examples of the correct behaviour, enabling reflection, goal-setting, and tracking of one's progress (Lehto \& Oinas-Kukkonen, 2015; Lehto et al., 2012). Therefore, it is likely that the more a system supports users in meeting their primary objective, the more they will feel competent and continue to use the system. We propose the following:

H2a: Primary task support positively affects perceived competence.

H2b: Primary task support positively affects continuance intention. 


\section{Social support}

Social support features motivate users by leveraging social influence, especially as social relationships are increasingly maintained and nurtured through computer-mediated communications (Lehto \& Oinas-Kukkonen, 2015). For this study, a modification of one indicator from social learning, another from social cooperation (Stibe \& Oinas-Kukkonen, 2014), and a self-developed item were used to measure social support. Adding social elements can have a positive effect on a target behaviour and enhance the effectiveness of a persuasive system (Chiu et al., 2009). Social support is also an important antecedent to self-efficacy; therefore, individuals who perceive they have received more social support are likely to have higher selfefficacy beliefs, which has a positive influence on the individuals' competence (Anderson, Winett, \& Wojcik, 2007; Bandura, 2004). Thus, we hypothesize:

H3: Social support positively affects perceived competence.

\section{Perceived credibility}

Perceived credibility deals with designing credible and subsequently more persuasive systems. Perceived credibility comprises trustworthiness, expertise, surface credibility, real-world feel, authority, third-party endorsements, and verifiability (Oinas-Kukkonen \& Harjumaa, 2009). Research has shown that understanding how users perceive the credibility of reviews, for example, is important for the survival and development of online discussion forums (Cheung, Luo, Sia, \& Chen, 2009). Cheung et al. (Cheung et al., 2009) found that a high level of electronic word-of-mouth review credibility enhances users' adoption desires for online recommendations, ultimately leads to continuous use, and attracts repeat visits to other consumer recommendations forums (Cheung et al., 2009). The more trustworthy a system is, the more likely a user's feelings 
of competence is enhanced. Therefore, we propose the following:

H4a: Perceived credibility positively affects perceived competence.

H4b: Perceived credibility positively affects continuance intention.

\section{Perceived competence}

Competence is the desire to feel a sense of satisfaction and effectiveness in attaining important results (Deci \& Ryan, 2000). Perceived competence is one of the three fundamental needs proposed in the self-determination theory (Deci \& Ryan, 2000). Perceptions of competence are theorized to be important because they facilitate people's goal attainment and provide them with a sense of need satisfaction from engaging in an activity at which they feel effective (Ho, 2010; Sørebø, Halvari, Gulli, \& Kristiansen, 2009; Williams et al., 1998). Of the three psychological needs, competence was found to be the most important in affecting attitudes towards using an elearning platform (Ho, 2010). This is because competence can make expectations increasingly realistic and usage increasingly efficient. When realistic expectations of a system and efficient usage converge, a high level of confirmation, i.e., realisation of the expected benefits of, for example, using an online system for commitment, may be a likely outcome (Ho, 2010). Therefore, the more competent one feels, the more likely one is to continue with an activity-in this case, the more willing they are to continue using the system if it helps them to fulfil their goals. Consequently, we propose:

H5: Perceived competence positively affects continuance intention.

\section{Research Methodology}

\section{Study context}

The artefact under examination in the present study is a Web-based Quantified Self (self-tracking 
data collection and visualization) with commitment contracts system (Figure 2). The system is primarily based on goal setting and encouraging frequent micro tasks based on users' daily routines and habits. The system allows one to create a contract to either spend less or more time on a particular activity and if one does not stick to their goal(s) they are charged. The system adds real consequences for not meeting planned goals.

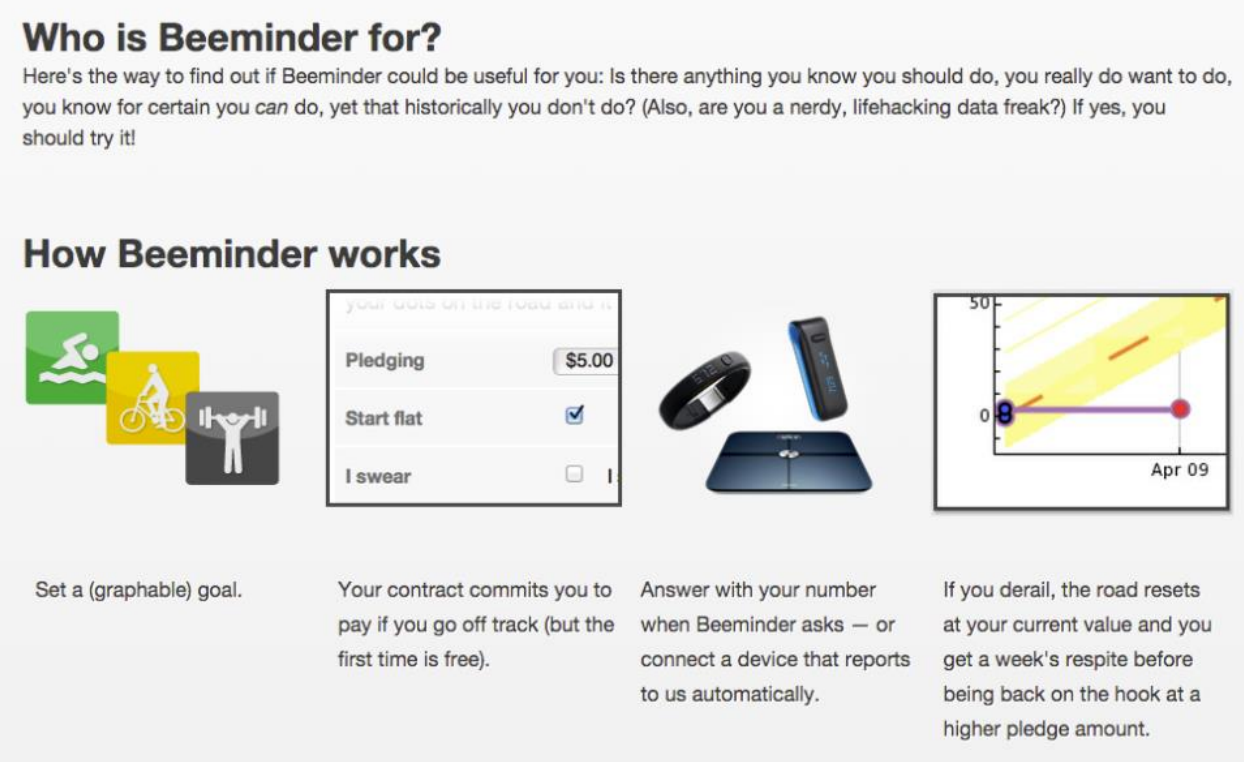

Figure 2. The Study Context

The system encourages consistency by allowing users to commit to specific goals for specific periods of time. Users can work on either single or multiple goals simultaneously and the data entry into the system is both manual and automated. There are multiple integration options where data from other systems are automatically retrieved and plotted in the system. Progress is plotted on a graph that is easily accessible from one's account either through mobile devices or online. If the individual stays on track, then the service is free; however, if the individual goes off track, then he or she pledges money to continue using the system in order to progress with his or her goal. If the individual goes off track again, he or she is charged. Users 
can change or delete their set goals after a week from requesting such a change if they cannot work on the goals set previously. The week's buffer enables the users to contemplate more clearly what they would like to achieve and is suitable for them. End dates for the user goal(s) can also be set. A summary of the artefact's persuasion context is presented in Table 2 in the previous section and further description of the system can be found in Appendix 2.

\section{Data Collection and Respondent Characteristics}

Between March and December 2016 (first between March and May and then between October and December), an online survey of the system users was conducted. Data were collected using an online software tool (Webropol). Participants were recruited through a public link that was sent to their email addresses. We first shared this link with the owner of the system who then sent it to the users. This ensured that the participants had already experience with the system. For the second round of data collection, participants were entered in a draw for a hundred-dollar Amazon gift card as an incentive for their participation. The first round of data collection had a total of 173 responses and the second round had 54, giving a total of 227 responses without missing data. The survey was opened by a total of 1009 respondents (523 in the first round and 486 in the second) of which 227 responded; thus, the effective response rate was $22.5 \%$ (227/1009).

The survey had two main parts. The first part consisted of demographic questions and questions related to the main goal tracked, whether having to pay a fee for not attaining their goal encouraged them to work harder, use history, and use frequency. The main goal(s) tracked were the default broad categories given in the system. For example, under fitness and training, it is possible to track different activities such as jogging, walking, cycling etc. and the output of these different activities would be plotted in the system. $74 \%(139 / 172)$ of those who responded to 
having to pay a fee for not meeting their goal stated that this motivated them and some even switched to the premium plan which offers more options. Overall, $74 \%$ of the respondents were male, about $52 \%$ were 30 years old or younger, and $85 \%$ had at least an undergraduate degree. Tables 3 and 4 present the respondents' characteristics.

Table 3. Respondent Characteristics

\begin{tabular}{|c|c|c|c|}
\hline & & Frequency & Percent $(\%)$ \\
\hline \multirow[t]{3}{*}{ Gender } & Male & 168 & 74.0 \\
\hline & Female & 54 & 23.8 \\
\hline & Unspecified & 5 & 2.2 \\
\hline \multirow[t]{4}{*}{ Age } & 30 or under & 117 & 51.5 \\
\hline & $31-40$ & 67 & 29.5 \\
\hline & $41-50$ & 31 & 13.7 \\
\hline & 50 and older & 12 & 5.2 \\
\hline \multirow[t]{5}{*}{ Education } & High school and Vocational training & 33 & 14.6 \\
\hline & Bachelor's degree & 94 & 41.4 \\
\hline & Master's degree & 58 & 25.6 \\
\hline & Other advanced degree & 9 & 4.0 \\
\hline & Doctoral degree & 32 & 14.1 \\
\hline
\end{tabular}

Table 4. System version, main goal, and use history

\begin{tabular}{|l|l|l|l|}
\hline & & Frequency & Percent \\
\hline
\end{tabular}




\begin{tabular}{|l|l|l|l|}
\hline Version & Free plan & 152 & 67.0 \\
\cline { 2 - 4 } & Bee Lite & 23 & 10.1 \\
\cline { 2 - 4 } & Plan Bee & 41 & 18.1 \\
\cline { 2 - 4 } & Beemium & 11 & 4.8 \\
\hline Goals & Fitness and training & 42 & 18.5 \\
\cline { 2 - 4 } & Health & 51 & 22.5 \\
\cline { 2 - 4 } & Productivity & 107 & 47.1 \\
\cline { 2 - 4 } & Learning & 27 & 11.9 \\
\hline Use history & 6 months or less & 49 & 21.6 \\
\cline { 2 - 4 } & 6 months to a year & 27 & 11.9 \\
\cline { 2 - 4 } & 1 to 2 years & 48 & 21.1 \\
\hline & 2 years to 3 years & 44 & 19.4 \\
\hline & 3 or more years & 59 & 26.0 \\
\hline \multirow{5}{*}{} & & & \\
\hline
\end{tabular}

The second part of the survey was the measurement instrument (Appendix A) consisting of seven-point Likert scale items (ranging from strongly disagree to strongly agree). The measurement instrument was used to examine users' perceptions of the persuasive software features and their influence on continued use of the system. Related to this, respondents were also asked in an open text question "What new features/services could the system offer that would add significant value to their use?” 


\section{Data Analysis and Results}

The research model was analysed using the structural equation modelling (SEM) approach, namely, PLS, a technique for simultaneously estimating relations among multiple constructs. SmartPLS software (Ringle, Wende, \& Becker, 2015) was used for the data analysis. PLS-SEM is appropriate when the purpose is to predict, rather than to test established theory, is suited for exploratory purposes and uses very general soft distributional assumptions (Chin, 2010; Hair Jr, Hult, Ringle, \& Sarstedt, 2013) PLS-SEM is a variance based approach composed of two steps: The first step assesses the measurement model, that is, analyses the relation of each indicator with its corresponding constructs. In the research model, all of the constructs were reflective and measured with at least two indicators. Reflective measurement models are typically assessed in terms of their internal consistency, reliability, and validity. If the measurement model meets the specified criteria, then the second step, the structural model, evaluates the hypothesized relations between the constructs. The evaluation of the predictive capabilities of the structural model is based on the significance of the path coefficients and the relations between the constructs (Hair Jr et al., 2013).

In addition to conducting a SEM analysis, open text responses to gather users’ perspectives on the suggestions for features that could significantly add value to the system and the reasons they had to pay a fee at any point during their use of the system were also analysed. These were optional so not all respondents answered the questions. The results results are presented after those of the SEM analysis.

\section{Measurement Model}

The measurement model represents the relation between constructs and their corresponding 
measures. Constructs' properties are assessed in terms of their validity and reliability, and measurement items that are not at acceptable levels are removed. Evaluating the measurement model addresses internal consistency (the composite reliability), indicator reliability, convergent validity, and discriminant validity. Reliability and consistency are measured using Cronbach's alpha and composite reliability with values ranging between 0 and 1 . High values indicate higher levels of reliability, and values higher than the typically applied threshold of 0.7 are acceptable (Fornell \& Larcker, 1981). For composite reliability, values from 0.6 to 0.7 are acceptable in exploratory research, while in more advanced stages of research, values between 0.7 and 0.9 are considered satisfactory. A value of 0.95 , however, indicates unnecessary redundancy in the construct items (Hair Jr et al., 2013), and any value above this number should be omitted from the construct to decrease the composite reliability to 0.95 or below.

The inter-construct correlations and the square root of the average variance extracted (AVE) show that all the constructs share more variance with their indicators than with other constructs. This, in addition to the indicators' factor loadings, is a good measure of convergent validity - the extent to which two or more items measure the same construct (Bagozzi \& Phillips, 1982). High loadings indicate that the measurement items correctly measure the same phenomenon and share a high proportion of variance (Hair Jr et al., 2013). Items with outer loadings below 0.6 were omitted (in primary task support and dialogue support). The AVE values for all the constructs were above the suggested minimum of 0.5 (Fornell $\&$ Larcker, 1981). The validity and reliability results are presented in Table 5.

Table 5. Reliability and validity of the constructs

\begin{tabular}{|l|l|l|l|l|l|l|l|l|l|l|}
\hline & CA & CR & AVE & VIF & COMP & CONT & CRED & DIAL & PRIM & SOCI \\
\hline
\end{tabular}




\begin{tabular}{|l|l|l|l|l|l|l|l|l|l|l|}
\hline COMP & 0.882 & 0.913 & 0.737 & 1.157 & $\mathbf{0 . 8 5 8}$ & & & & & \\
\hline CONT & 0.896 & 0.928 & 0.765 & 1.158 & 0.302 & $\mathbf{0 . 8 7 4}$ & & & & \\
\hline CRED & 0.923 & 0.946 & 0.815 & 1.199 & 0.081 & 0.173 & $\mathbf{0 . 9 0 3}$ & & & \\
\hline DIAL & 0.667 & 0.817 & 0.598 & 1.271 & 0.145 & 0.192 & 0.260 & $\mathbf{0 . 7 7 4}$ & & \\
\hline PRIM & 0.685 & 0.824 & 0.614 & 1.598 & 0.344 & 0.535 & 0.279 & 0.371 & $\mathbf{0 . 7 8 4}$ & \\
\hline SOCI & 0.749 & 0.852 & 0.660 & 1.151 & 0.096 & 0.161 & 0.196 & 0.308 & 0.175 & $\mathbf{0 . 8 1 2}$ \\
\hline
\end{tabular}

\section{Structural Model}

Assessing the structural model determines how well the empirical data support the theory, showing the relations between different constructs and specifying how the constructs are related (Hair Jr et al., 2013). The key results are the path coefficients and the $\mathrm{R}^{2}$ values, which represent the hypothesized relations among the constructs and the percentage of the total variance of the dependent variable explained by the independent variables. The complete bootstrapping method with 5,000 resamples and parallel processing with no sign changes was used. Two-tailed biascorrected and accelerated (Bca) bootstrap was the confidence interval method used. Nearly all path coefficients are significant up to the .05 level (Table 8). Figure 2 presents the results of the path model analysis. 


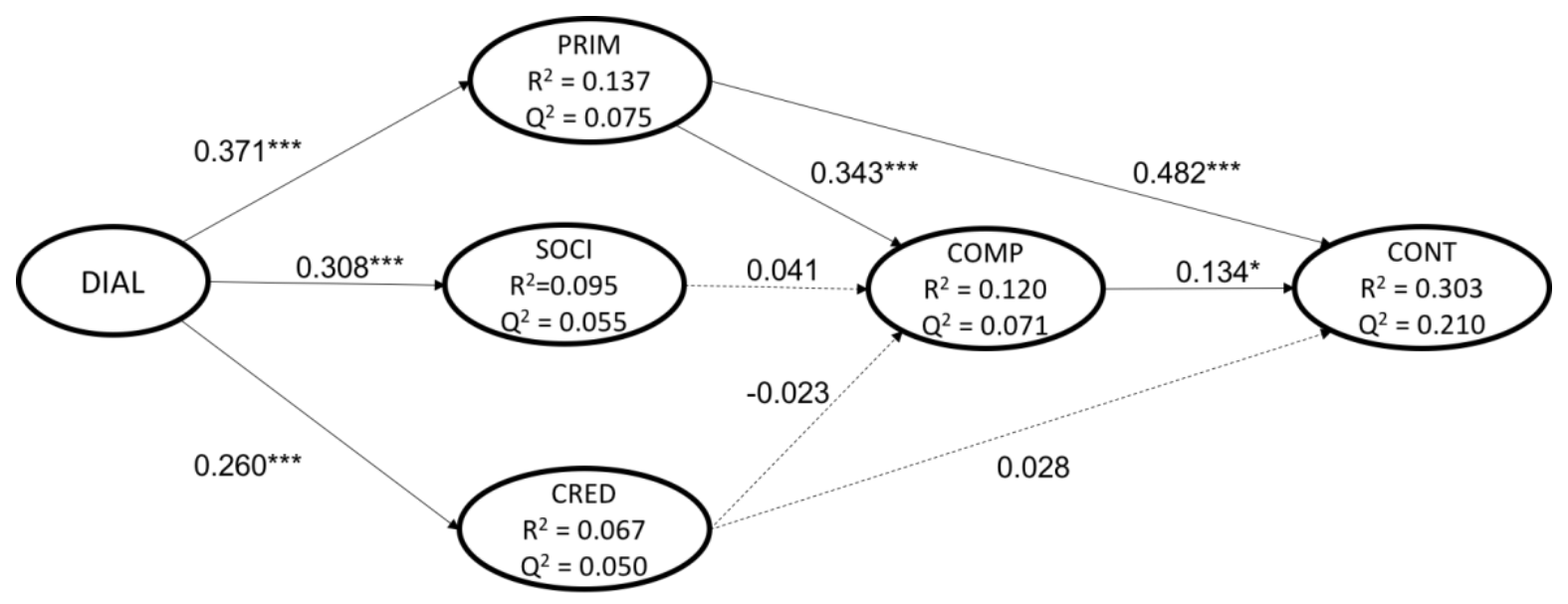

Figure 3. Structural Model

Note:

------: insignificant relationship, ${ }^{*} p<.05, * * * p<.001$

The results of the PLS analysis (Fig 2) provide moderate support for the research model. Six (H1a, H1b, H1c, H2a, H2b, H5) of the nine hypotheses were supported and primary task support and social support explain $11 \%$ of the variance in perceived competence. Dialogue support explained $13.7 \%$ of the variance in primary task support, about 10 and $7 \%$ of the variances in social support and perceived credibility. A substantial amount of the variance (30\%) in intention to continue using the system was explained by primary task support-perceived competence explains a minimal amount of the variance and perceived credibility is not a strong predictor of intention to continue to use the system.

\section{Total Effects, Effect Sizes and Predictive Validity}

Table 6 shows the total effects (direct and indirect effects) and the effect sizes of each construct on the corresponding dependent variables' variance. Effect sizes determine whether the effects shown by path coefficients are small (.02), medium (0.15), or large (.35) (Cohen, 1988). Effect sizes below .02 are considered too weak to be relevant, which is the case for three hypotheses. 
Dialogue support has the highest total effect (with a medium effect size) on primary task support, whereas primary task support has the highest total effect on perceived competence (a medium effect size) and continuance intention (a large effect size). Dialogue support also has an indirect positive effect on perceived competence and continuance intention.

Table 6. Total effects and effect sizes $\left(f^{2}\right)$

\begin{tabular}{|l|l|l|l|l|l|}
\hline & COMP & CONT & CRED & PRIM & SOCI \\
\hline COMP & & $0.134(0.023)$ & & & \\
\hline CRED & $-0.023(0.001)$ & $0.028(0.001)$ & & & \\
\hline DIAL & 0.134 & 0.204 & $0.260(0.072)$ & $0.371(0.159)$ & $0.308(0.105)$ \\
\hline PRIM & $0.343(0.121)$ & $0.482(0.272)$ & & & \\
\hline SOCI & $0.041(0.002)$ & 0.005 & & & \\
\hline
\end{tabular}

The predictive relevance of the model was also assessed using Stone-Geisser's crossvalidated redundancy measure (the $\mathrm{Q}^{2}$ value). Values above zero for a certain reflective endogenous construct indicate the path model's predictive relevance for that particular construct (Hair Jr et al., 2013). Predictive relevance was demonstrated for all endogenous constructs, with continuance intention exhibiting moderately strong predictive validity (Table 7).

Table 7. Predictive relevance $\left(Q^{2}\right.$ values $)$

\begin{tabular}{|l|l|l|l|l|}
\hline COMP & CONT & CRED & PRIM & SOCI \\
\hline 0.071 & 0.210 & 0.050 & 0.075 & 0.055 \\
\hline
\end{tabular}

\section{Subgroup Analysis}

The study also conducted subgroup analysis to investigate how the perception of design principles vary between different groups. As understanding how the persuasive software features 
are perceived across user groups can help in personalizing behaviour change interventions thereby increasing their effectiveness (Orji, Vassileva, \& Mandryk, 2013). Further analyses identified different relationships for the constructs' path coefficients and explained variances in the groups analysed compared to the full sample (Tables 8 and 9). We conducted a subgroup analysis by dividing the full sample into two groups: gender and goals (referring to the main user goals tracked by the system) (Table 2).

An analysis of the results presented in Tables 8 and 9 indicate that there were few differences in the subgroups when compared to the full sample. There were significant differences between genders in the paths from dialogue support to primary task support and dialogue support to social support (a stronger influence in females). This corresponds with the findings in Orji et al. (2013) which found the determinants of healthy eating to vary across gender. Thus, pointing to the potential role gender, users' values, individual differences or the problem domain could have on the effects of the persuasive features and the importance of accommodating the needs of different user groups (Halttu \& Oinas-Kukkonen, 2017; Schneider et al., 2016). This is highlighted in user a response to the question of having to pay a fee for not meeting a planned goal where it was stated that: "the productivity system/commitment device proposed isn't compatible for my circumstances (e.g. no income source as a student) and (in my opinion) isn't an appropriate system to use for people in difficult circumstances (e.g. long-term cognitive dissonance ala mental illness, apathy, repeated failures in self-improvement, etc.)'.

In all the goals, the paths from dialogue support to primary support were supported at varying levels of significance and in the health goals, dialogue support compared to the other goals explained a significant amount of variance (33\%) in social support.

\section{Table 8. Path coefficients ( $\beta$ ) for the Subgroups and the Full Sample}




\begin{tabular}{|c|c|c|c|c|c|c|c|}
\hline & Males & Females & & Goals & Tracked & & Total \\
\hline & & & Fitness & Health & Productivity & Learning & \\
\hline $\begin{array}{l}\text { COMP- } \\
>\mathrm{CONT}\end{array}$ & 0.124 & 0.236 & 0.082 & 0.121 & 0.103 & 0.263 & $0.133^{*}$ \\
\hline $\begin{array}{l}\text { CRED- } \\
>\text { COMP }\end{array}$ & 0.017 & -0.162 & -0.006 & -0.053 & -0.016 & -0.240 & -0.023 \\
\hline $\begin{array}{l}\text { CRED- } \\
>\mathrm{CONT}\end{array}$ & 0.013 & 0.008 & 0.136 & $0.361^{*}$ & -.0080 & -0.127 & 0.028 \\
\hline $\begin{array}{l}\text { DIAL- } \\
>\text { CRED }\end{array}$ & $0.270 * * *$ & 0.167 & $0.500 * * *$ & 0.035 & $0.380^{* * *}$ & -0.150 & $0.260 * * *$ \\
\hline $\begin{array}{l}\text { DIAL- } \\
\text { >PRIM }\end{array}$ & $0.330 * * *$ & $0.533^{* * *}$ & $0.470^{*}$ & $0.490 * * *$ & $0.274 * *$ & 0.660 & $0.371 * * *$ \\
\hline $\begin{array}{l}\text { DIAL- } \\
>\text { SOCI }\end{array}$ & $0.280 * * *$ & $0.405^{* * *}$ & 0.184 & $0.570 * * *$ & $0.272 *$ & 0.300 & $0.308 * * *$ \\
\hline $\begin{array}{l}\text { PRIM- } \\
>\text { COMP }\end{array}$ & $0.351 * * *$ & $0.330^{*}$ & $0.473 * * *$ & 0.381 & $0.382 * * *$ & 0.166 & $0.343^{* * *}$ \\
\hline $\begin{array}{l}\text { PRIM- } \\
>\mathrm{CONT}\end{array}$ & $0.500 * * *$ & $0.400 * *$ & $0.540 * * *$ & $0.360^{* *}$ & $0.584 * * *$ & 0.432 & $0.482 * * *$ \\
\hline $\begin{array}{l}\text { SOCI- } \\
>\text { COMP }\end{array}$ & 0.0701 & 0.080 & $0.290^{*}$ & -0.180 & 0.008 & 0.102 & 0.039 \\
\hline & 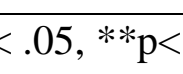 & $1, * * * \mathrm{p}<$ & & & & & \\
\hline
\end{tabular}


Note. The sample size for the learning goals did not meet the 10-times largest number of incoming paths for any dependent variable threshold (Gefen, Rigdon, \& Straub, 2011; Hair Jr et al., 2013), but this did not adversely affect the analysis.

Table 9. Variances $\left(\mathbf{R}^{2}\right)$ for the Subgroups and the Full Sample

\begin{tabular}{|l|l|l|l|l|l|l|l|}
\hline & \multirow{2}{*}{} & & & & \multicolumn{5}{|c|}{ Males } & Females & \multicolumn{5}{|l|}{ Total } \\
\cline { 4 - 7 } & & & Fitness & Health & Productivity & Learning & \\
\hline COMP & 0.141 & 0.101 & 0.350 & 0.125 & 0.143 & 0.102 & 0.112 \\
\hline CONT & 0.311 & 0.270 & 0.390 & 0.410 & 0.373 & 0.345 & 0.303 \\
\hline CRED & 0.070 & 0.0279 & 0.250 & 0.001 & 0.145 & 0.022 & 0.067 \\
\hline PRIM & 0.190 & 0.285 & 0.220 & 0.240 & 0.075 & 0.433 & 0.137 \\
\hline SOCI & 0.080 & 0.164 & 0.034 & 0.330 & 0.074 & 0.082 & 0.095 \\
\hline
\end{tabular}

\section{Control variables}

To test the robustness of the findings regarding the BCSS's continuance intention, four control variables (age in years, system version, and use history) were included as supplementary predictors of perceived competence and continuance intention. None of the control variables were found to be significant when they were simultaneously incorporated into the model. The variance explained $\left(R^{2}\right)$ for both perceived competence and continuance intention slightly increased with the addition of the control variables. Without the control variables, the variance for perceive competence was $12 \%$ and with the control variables it was 13.1 percent. For continuance intention, it was $30.3 \%$ without and 31.5 with the control variables. 


\section{Common method bias}

As a cross-sectional survey was used and all the variables were measured using a similar instrument, common method bias (CMB) Podsakoff, MacKenzie, Lee, \& Podsakoff (2003) poses a threat to the validity of results. $\mathrm{CMB}$ is attributable to the measurement method rather than to the constructs the measures represent and method biases are a problem because they are one of the main sources of measurement error (Podsakoff et al., 2003). Podsakoff et al. (2003), provide a number of suggestions on how to avoid the introduction of common method bias during data collection. To minimise CMB ex ante, the respondents were assured of their anonymity and confidentiality of the study and they were asked to answer questions as honestly as possible. Data was also collected at two different points in time and the questionnaires included reversecoded items to reduce acquiescence (Podsakoff et al. 2003).

For ex post assessment of CMB Kock \& Lynn (2012), proposed the full collinearity test as a comprehensive procedure for the simultaneous assessment of vertical and lateral collinearity. Through this procedure variance inflation factors (VIFs) are generated for all latent variables in a model. The occurrence of a VIF greater than 3.3 is proposed as an indication of pathological collinearity, and also as an indication that a model may be contaminated by CMB. Therefore, if all VIFs resulting from a full collinearity test are equal to or lower than 3.3, the model can be considered free of CMB (Kock, 2015), which is the case for our research model. See Table 5 for results of the collinearity test.

\section{Synthesis of the open text responses}

The goal of analysing the open text responses was to gain a better understanding of the improvements that could be made to the investigated system, users' thoughts on having to pay 
for derailing on their goals, and to provide an overview of their perspectives through quotes. $73 \%(166 / 227)$ responded to the former question and 56\% (126/227) responded to the second. Below, we provide the categorisation of these responses and relate them to user's perceptions of the system's elements and how it could be improved. The responses were coded according to whether they were related to commitment or to specific persuasive features outlined in the PSD model (Oinas-Kukkonen \& Harjumaa, 2009).

\section{Commitment and consistency}

Among the key postulates outlined in the PSD model is that of people liking their views about the world to be organized and consistent (Oinas-Kukkonen \& Harjumaa, 2009). If systems support the making of commitments users will more likely be persuaded. Commitment and consistency become important because inconsistency may motivate behavior change (OinasKukkonen \& Harjumaa, 2009). Consistency is engaged by commitment (to take a stand). And once a stand is taken, there is a natural tendency to behave in ways that are consistent with the stand (Cialdini, 2007). The artefact investigated in this study is designed to hold people accountable for their decisions; it encourages consistency in decision-making by encouraging users to set small easily achievable goals that they are willing to be penalised for if they don't meet.

Many of the responses to the question of whether having to pay a fee for not meeting their goal were in the affirmative. For some, it is this form of hard commitments Reeves (2011), that made them to think more about some of their goals and motivated them to continue with these goals even after derailing: 
Once actual money is at stake, the bright line that separates success from failure matters much more, and in turn I get things done. I want to keep it that way: If I didn't pay up, future pledges would feel like there is no money really at stake.

Because the motivation that I get from tracking the goals is worth paying them when I derail. Because the work I get done is more valuable than the amount I pay.

For others, adding a monetary consequence for derailing got them to reflect on (Halttu \& OinasKukkonen 2017) the importance of the goal(s), on why they derailed, whether the goal(s) was really benefiting them, or it was just any other activity they would not mind giving up or one they tried and realized they do not like. This highlights interactive technologies' ability to create conditions that encourage reflection and that can lead to tangible results for the users (Halttu \& Oinas-Kukkonen, 2017). In a sense, because the users had to pay if they derailed on a goal, they carefully had to consider which activities are important for them. This is reflected in the quote below:

So that it would continue to work as a commitment device, and in part, to shame myself into doing what I said I was going to do. The money would also sometimes help me see that goals I thought were important to me weren't too important to me. If I would rather give ... \$30 than practice Ukulele for 20min, perhaps it's a hobby I can feel okay about giving up.

I've derailed a LOT of times! Sometimes because it seemed worth the money to have the peace of mind to skip a task, other times because even in my panic I couldn't manage the task in time.

In order for the system to be even more useful, some suggested ways in which committing to goals could be simplified and even recognized when and why they were failing to meet their goals. They also did not want to renege on their commitments as once a stand is taken, there is a natural tendency to behave in ways that are stubbornly consistent with the stand (Cialdini, 2007). 
I agreed to the commitment, and it would be ineffective if I didn't follow through with it.

I've derailed a LOT of times! Sometimes because it seemed worth the money to have the peace of mind to skip a task, other times because even in my panic I couldn't manage the task in time.

I failed to stay on my road and the payment was me making good on my commitment to myself and to...

The system seems to perform well in encouraging users to be consistent in their goals and when they fall short, the immutable monetary consequence (risk of losing their money) Rogers et al. (2014) is enough to keep some on the right track.

\section{Feature recommendations}

For the most part, users found the system useful and easy to use. Although, some thought it could be more beneficial if it was better tailored to users' needs. An important design consideration is to accommodate the needs of different user groups Schneider et al. (2016) and at least with the free version, there are not many options for accommodating diverse user groups. Even though users can pursue different goals, there isn't much differentiation in the system's features between these goals. Improvement suggestions were for the general goal-setting features and the possibility to track more specialised goals. In reference to features that support users to carry out the real-world activity they would like to complete (Oinas-Kukkonen \& Harjumaa, 2009) and better guidance to make sure that user goals are set well and better fit the intended activity.

The option of pre-paying, so that I can get a reward for achieving a goal rather than paying a penalty for not achieving it. I know that people are generally more loss averse than they are gain seeking, so such a set up may not be optimal, but I'd be curious to try it out. 
Better and more accurate tracking of more parameters and goals. For example. If I am learning Electric Engineering content, how can I track my progress efficiently, For specialised goals there is no much support now.

Change the goal settings so that you can specify more complex levels than $\mathrm{x}$ minutes a week or whatever, and instead be able to say, e.g., 1 thing every weekday.

Other than simplifying the goal-setting and tracking process, there were also suggestions for a better user experience, integration with more services and improved features that support communication between the users and the system by providing positive feedback as soon as people start using them (Oinas-Kukkonen \& Harjumaa, 2009; Rogers et al., 2014). These included:

Rewards - a system for rewarding the user for doing more than the absolute minimum. Encourage users to build a big buffer through rewards

Reminders that would zeno-poll towards a time that was earlier than the actual deadline by a (configurable) number of minutes per outstanding unit of work... that is, reminding me when I need to *start* working, not when I need to have *finished*

Currently, the system does not offer good opportunities for groups of friends or similar others to share their results or offer each other support. Each individual can set their own goals and progress at their own pace, but there are no good opportunities for a group of friends to pursue the same goals concurrently if they would like to. Some suggestions to improve this included:

Goals shared by multiple users

Beeminder intergrates very well with other services at a data level, but it would be good for it to integrate at a social level as well somewhat. I'm not sure how though. Using Beeminder is often a lonely activity. Maybe a possibility to add "Friends" that are other Beeminder users, then you could see when others are in the red or yellow or something, offer some 
words of encouragement and motivation to them. This could be done either within Beeminder or by integrating into an external service somehow...

To meaningfully improve the efficacy of online systems that support the enforcement of commitments, they will need to be engineered to be more effective. A suggestion, especially for a system such as the one investigated in this study, is to make the penalties involve a range of consequences beyond just monetary losses. Leveraging the influence of existing social networks by creating social, in addition to monetary, consequences for failing to achieve goals will likely increase their appeal (Rogers et al., 2014).

\section{Discussion}

In this study, we investigated factors influencing the decisions to use a BCSS for commitment. We conducted an online questionnaire with 227 responses and used PLS-SEM to examine the applicability of PSD in explaining users' perceived competence and how PSD and competence influence users' intention to continue using a Web-based BCSS for commitment. The study adopted a feature-centric view that advocates the examination of a system's features rather than the bundle of features available as it is the specific features in use at any point in time that determine the overall experience and whether users meet their goals (Al-Natour \& Benbasat, 2009). Open text responses were also analysed to gather users' perspectives on the improvements that could be made in the same and on the importance of the commitment aspect of the system. From this analysis, it was evident that the monetary consequence for not meeting set targets was a good motivator.

A subgroup analysis was also done to study whether there were any differences between groups (gender and users' goals) and the effect this had on the coefficients and variances. When considering the variances for endogenous constructs there were differences in and within the 
subgroups as compared to the full sample with some constructs fluctuating. This suggests the PSD constructs are to some extent perceived differently between genders and depending on the goal type, some features might be more important than others. Therefore, it is important to integrate the needs of different user groups. This can be done through, for example, implementing an adaptive interface or ensuring that different usage styles are possible in one interface (Schneider et al., 2016).

All relations (Fig 2) except H4a (perceived credibility positively affects perceived competence) were found to be positively related. However, two of the positive relations and $\mathrm{H} 4 \mathrm{a}$ (which was negative) had very low path coefficients $(0.039,0.027$, and -0.023$)$ values meaning the practical significance of the associations is very low. These findings extend the literature on adoption and continuance intentions for persuasive systems (Lehto \& Oinas-Kukkonen, 2015; Lehto et al., 2012; Stibe \& Oinas-Kukkonen, 2014) by identifying primary task support as an important predictor of perceived competence and continuance intention. This is consistent with findings in Lehto and Oinas-Kukkonen's (2015) post-hoc analysis of simpler path models that test the effect of PSD features on use continuance.

The five positive relations (dialogue support predicts primary task support, social support, and perceived credibility and primary task support predicts perceived competence and continuance intention) demonstrate the important role of PSD in use continuance. In line with previous studies (Halttu \& Oinas-Kukkonen, 2017; Kelders et al., 2012; Langrial et al., 2013; Ritterband et al., 2009) that showed the importance of dialogue support, it was also shown in the present study to be an important factor in evaluating the effectiveness of a system. The latter two relations (primary task support as a predictor of competence and continuance) indicate that 
supporting a user's primary goal likely leads to him or her feeling more competent and increases the likelihood of continued use.

Interestingly, the direct effect between social support and perceived competence is weak, in contrast to that in (Anderson et al., 2007), for example, who found that social support had an indirect total effect on users' nutrition through self-efficacy and self-regulation. This result may be due to the unique nature of the system compared with other persuasive systems and the social support construct itself. Two measurement items for the construct referred to the perception of support through the system, and the self-developed item was social support mediated by the system (Appendix 1). On the questionnaire, there was also a question asking users whether they had social supporters (self-appointed peers who can follow up on users' progress as this is an optional feature in the system), and $71 \%$ (161) replied no. This can help explain the statistically insignificant relation between social support and perceived competence as not many of the respondents perceived or had social support.

This view is further supported by analysis of the open text responses in which some users noted the lack of social support features. A suggestion for improvement was for the system to offer better social engagement options, a way to share goals that encourages cooperation and enhanced social support. The problem domain can also have an effect as leading to differences in intervention characteristics between health care areas and in the perception of an intervention's persuasive features. There could be differences between web-based interventions aimed at people with chronic conditions, at lifestyle and general well-being changes, or at mental health because of the target group, involvement of healthcare professionals, and the duration of the particular interventions. However, the underlying design principles could be the same (Kelders et al., 2012). 
The relation between perceived competence and continuance intention, although positive, was low which warrants further investigation. Especially as perceived competence was found to be the strongest of the three psychological needs in predicting the intention to continue using elearning technology (Ho, 2010; Sørebø et al., 2009). A possibility, as it is one of the three psychological needs (Deci \& Ryan, 2000), is to extend the present model with these other psychological constructs, examine how they correlate with the PSD features, and affect continuance intention. Although the self-determination theory posits that intrinsic motivation is the prototype for self-determined behaviour, there is also recognition that there might be moments when extrinsic motivation is required (Deci \& Ryan, 2000). Therefore, extending the present model with the other constructs might also help to better examine whether there are significant differences between goal type and the psychological needs. The surprisingly negative but statistically insignificant relation between perceived credibility and perceived competence and the insignificant positive relation with continuance intention in contrast to Lehto and OinasKukkonen (2013) and Cheung et al. (2009) also warrants further attention.

The results from the open text response analysis also revealed how systems that encourage users to be consistent in their decision making can better facilitate behaviour change. When some users derailed on a goal, they seemed to reflect on the reasons for this and whether their goal was important if at all. The monetary consequence was also a motivator as people are inherently loss averse as was stated in one of the comments and was shown in Kahneman and Tversky's (1979) seminal studies. Reflection is rarely the intent for BCSSs and it has been suggested in Halttu and Oinas-Kukkonen (2017) that systems that cause users to reflect on their actions can lead to different actions. Therefore it is important to understand the impact of 
persuasive software features and the interactions between them on users' reflection (Halttu \& Oinas-Kukkonen, 2017).

\section{Implications}

Using the PSD model (Oinas-Kukkonen and Harjumaa, 2009), the study extends previous research on use continuance of persuasive systems by looking at the effect of the persuasive design principles on users' perceived competence and continuance intention of an online system for commitment. Persuasion can also be considered as a process and these design principles provide techniques to further learn about users and their changing goals, which is important in systems such as the one investigated where users have different objectives and motivations. PSD directs attention to the characteristics or features of technology that may restrict or guide users' actions in certain ways and it is important to consider users' interaction with different features of technology and how technology on its own can act as an environmental cue by triggering automatic action (de Guinea \& Markus, 2009).

A system's use in a particular interaction also forms the basis for how it is perceived and evaluated by its users. For example, persuasive features provide options on how a system can be used, but it is users' choices in terms of how they use the system that determines the relevance of the evaluative criteria used to assess the system and the perceptions users form about the system during their interactions (Al-Natour \& Benbasat, 2009). There could also be a conflict between the virtual and physical as a limitation of technology is that it is not comprehensive and does not cater for a broad range of actions that a user may undertake. Therefore, it is important for the developers of persuasive systems to understand and recognise that lifestyle behaviour change is often a long term endeavour that permeates everyday life, including the social world (Consolvo et al., 2009). 
Practically, the study highlights the importance of considering a system's primary intent and how this can be translated to software features that help users to achieve their main goal(s) as not all users have uniform backgrounds. And a reason for non-adoption or discontinued IS use could be the lack of "feature-function fit" (Markus \& Tanis, 2000) between users' needs and the system's features. Therefore, it is important to understand users' relationship with a persuasive system to fully understand their decision to continue using the system, the nature of that usage and why it is being used in a certain way (for a particular goal) (Al-Natour \& Benbasat, 2009).

\section{Limitations and Future Research}

The study had several limitations. First, some of the relations in the model, even some of those shown to be strong in previous research, have lower or statistically insignificant values. A pilot study prior to publishing the survey where the measurement instruments are tested could have helped to improve factor loadings and the path coefficients between some constructs. Future research should examine the weaker links more closely. A second limitation is that the research model was applied to only one system. Thus, caution should be exercised about the generalization of the findings to other contexts.

Also, even though the survey was distributed to all the users of the system, it is likely that only the most active in the community filled the survey which could cause a bias in the results. Selection bias is a major factor that limits the generalisability of results as surveys rely on selfreport and people are more likely to respond if there are items of interest to them or because they are attracted by the incentives offered for participation (Eysenbach \& Wyatt, 2002). There were no incentives in the first survey, therefore it is likely that the respondents were interested in the items in question. The second survey had an incentive, but this did not seem to encourage participation as there were much less respondents. 
As noted in de Guinea and Markus (2009) and related to the previous point, self-report techniques are not well-suited to obtain valid individual-level processes that take place outside of people's awareness. Therefore, future research should employ different procedures, such as further subgroup analysis and application of constraints for data selection, observational studies and experiments to better explain the effects of the various PSD strategies on user behaviour. As the system investigated supported the pursuance of different goals, how carrying out these different goals is supported by PSD as some goals might require different forms of engagement and how this can help in changing long-term behaviour should be addressed in future research.

Considering the study also focused on continued use and interactions with the individual over time, a longitudinal research design would have been appropriate. Even though we collected data at two points in time, it was analysed in a cross-sectional manner because it was based on different samples and the second round of data collection had a considerably fewer response rate compared to the first. Future research should more specifically analyse the impact of time on the data collection. Based on a similar sample, additional analysis could be conducted to determine whether they are changes in the perceived support of the system over time and how this influences users' continuance intention.

Lastly, the sample also showed a bias toward male respondents, with $74 \%$ male. It is possible that male users possess goal-oriented characteristics, such as decisiveness, whereas female users place more emphasis on emotive qualities or hedonic value (Orji et al., 2013). To investigate the role of gender in the proposed model, we conducted a subgroup analysis of how the perception of the design principles varies between different groups. The results revealed there was a stronger influence in females in the path coefficients from dialogue support to primary task 
support and to social support. The model mostly appears to operate similarly across genders, but the difference in sample size between the two groups poses a threat to the validity of the results.

\section{Conclusion}

This study, in accordance with previous research provides evidence that persuasive system features are associated to varying degrees with users' perceived competence and continuance intention of a system. It also gives insights into the importance of considering how demographic characteristics, particularly gender can lead to different perceptions of the persuasive design features. Additionally, as people had different goals for using the system, these differences might require various forms of support and it is unwise to assume that the same design principles apply equally to all users. Further, as in several previous studies, dialogue support was found to have a crucial role in evaluating the effectiveness of the system as this feature strongly supports users' interactions with the system and facilitates completion of the primary tasks. Primary task support also strongly predicts users' confidence in their ability to carry out a task and their intention to continue using a system. Understanding the place of persuasive systems design in the context of fulfilling users' needs during user engagement with the systems can provide a means to counterbalance factors that lead to the non-adoption or failure of digital interventions, especially considering the nature of commitment systems in which something (usually of monetary value) is at stake if specific objectives are not fulfilled. Studying how persuasive systems design may enhance continued use is important for developing behaviour change interventions.

\section{References}

Al-Natour, S., \& Benbasat, I. (2009). The Adoption and Use of IT Artifacts: A New InteractionCentric Model for the Study of User-Artifact Relationships. Journal of the Association for 
Information Systems.

Anderson, E., Winett, R., \& Wojcik, J. (2007). Self-regulation, self-efficacy, outcome expectations, and social support: Social cognitive theory and nutrition behavior. Annals of Behavioral Medicine, 34(3), 304-312. https://doi.org/10.1007/BF02874555

Bagozzi, R. P., \& Phillips, L. W. (1982). Representing and Testing Organizational Theories: A Holistic Construal. Administrative Science Quarterly, 27(3), 459-489. https://doi.org/10.2307/2392322

Bandura, A. (2004). Health Promotion by Social Cognitive Means. Health Education \& Behavior, 31(2), 143-164. https://doi.org/10.1177/1090198104263660

Benbasat, I. (2010). HCI research: Future challenges and directions. AIS Transactions on Human-Computer Interaction, 2(2), 1.

Berkovsky, S., Freyne, J., \& Oinas-Kukkonen, H. (2012). Influencing Individually: Fusing Personalization and Persuasion. ACM Trans. Interact. Intell. Syst., 2(2), 9:1--9:8. https://doi.org/10.1145/2209310.2209312

Beshears, J. L., Choi, J. J., Laibson, D., Madrian, B. C., \& Sakong, J. (2011). Self control and liquidity: How to design a commitment contract.

Bhattacherjee, A. (2001). Understanding Information Systems Continuance: An expectationconfirmation Model. MIS Quarterly, 25(3), 351-370.

Briñol, P., \& Petty, R. E. (2009). Chapter 2 Persuasion. Advances in Experimental Social Psychology, 41, 69-118. https://doi.org/http://dx.doi.org/10.1016/S0065-2601(08)00402-4

Bryan, G., Karlan, D., \& Nelson, S. (2010). Commitment devices. Annu. Rev. Econ., 2(1), 671698.

Brynjarsdottir, H., Håkansson, M., Pierce, J., Baumer, E., DiSalvo, C., \& Sengers, P. (2012). Sustainably Unpersuaded: How Persuasion Narrows Our Vision of Sustainability. In Proceedings of the SIGCHI Conference on Human Factors in Computing Systems (pp. 947956). New York, NY, USA: ACM. https://doi.org/10.1145/2207676.2208539

Chatterjee, S., \& Price, A. (2009). Healthy Living with Persuasive Technologies: Framework, Issues, and Challenges. Journal of the American Medical Informatics Association : JAMIA, 
16(2), 171-178. https://doi.org/10.1197/jamia.M2859

Cheung, M. Y., Luo, C., Sia, C. L., \& Chen, H. (2009). Credibility of Electronic Word-ofMouth: Informational and Normative Determinants of On-line Consumer Recommendations. International Journal of Electronic Commerce, 13(4), 9-38. https://doi.org/10.2753/JEC1086-4415130402

Chin, W. W. (2010). How to Write Up and Report PLS Analyses. In V. Esposito Vinzi, W. W. Chin, J. Henseler, \& H. Wang (Eds.), Handbook of Partial Least Squares: Concepts, Methods and Applications (pp. 655-690). Berlin, Heidelberg: Springer Berlin Heidelberg. https://doi.org/10.1007/978-3-540-32827-8_29

Chittaro, L., \& Zangrando, N. (2010). The persuasive power of virtual reality: Effects of simulated human distress on attitudes towards fire safety. Lecture Notes in Computer Science (Including Subseries Lecture Notes in Artificial Intelligence and Lecture Notes in Bioinformatics), 6137 LNCS, 58-69. https://doi.org/10.1007/978-3-642-13226-1_8

Chiu, M.-C., Chang, S.-P., Chang, Y.-C., Chu, H.-H., Chen, C. C.-H., Hsiao, F.-H., \& Ko, J.-C. (2009). Playful Bottle: A Mobile Social Persuasion System to Motivate Healthy Water Intake. In Proceedings of the 11th International Conference on Ubiquitous Computing (pp. 185-194). New York, NY, USA: ACM. https://doi.org/10.1145/1620545.1620574

Cialdini, R. B. (2007). Influence: The psychology of persuasion. New York, NY, USA: HarperCollins Publishers.

Cohen, J. (1988). Statistical Power Analysis for the Behavioral Sciences (2nd Edition). Routledge.

Consolvo, S., McDonald, D. W., \& Landay, J. A. (2009). Theory-driven Design Strategies for Technologies That Support Behavior Change in Everyday Life. In Proceedings of the SIGCHI Conference on Human Factors in Computing Systems (pp. 405-414). New York, NY, USA: ACM. https://doi.org/10.1145/1518701.1518766

Corbett, J. Designing and Using Carbon Management Systems to Promote Ecologically Responsible Behaviors., 14 Journal of the Association for Information Systems 339-378 (2013). Association for Information Systems.

de Guinea, A. O., \& Markus, M. L. (2009). Why Break the Habit of a Lifetime? Rethinking the 
Roles of Intention, Habit, and Emotion in Continuing Information Technology Use. MIS Quarterly, 33(3), 433-444.

Deci, E. L., \& Ryan, R. M. (2000). The" what" and" why" of goal pursuits: Human needs and the self-determination of behavior. Psychological Inquiry, 11(4), 227-268.

DiSalvo, C., Sengers, P., \& Brynjarsdóttir, H. (2010). Mapping the Landscape of Sustainable HCI. In Proceedings of the SIGCHI Conference on Human Factors in Computing Systems (pp. 1975-1984). New York, NY, USA: ACM. https://doi.org/10.1145/1753326.1753625

Dourish, P. (2010). HCI and Environmental Sustainability: The Politics of Design and the Design of Politics. In Proceedings of the 8th ACM Conference on Designing Interactive Systems (pp. 1-10). New York, NY, USA: ACM. https://doi.org/10.1145/1858171.1858173

Drozd, F., Lehto, T., \& Oinas-Kukkonen, H. (2012). Exploring Perceived Persuasiveness of a Behavior Change Support System: A Structural Model. In M. Bang \& E. L. Ragnemalm (Eds.), Persuasive Technology. Design for Health and Safety: 7th International Conference, PERSUASIVE 2012, Link\{ö\}ping, Sweden, June 6-8, 2012. Proceedings (pp. 157-168).

Berlin, Heidelberg: Springer Berlin Heidelberg. https://doi.org/10.1007/978-3-642-310379_14

Ebermann, C., \& Brauer, B. (2016). The Role of Goal Frames Regarding the Impact of Gamified Persuasive Systems on Sustainable Mobility Behavior. ECIS 2016 Proceedings.

Eysenbach, G., \& Wyatt, J. (2002). Using the Internet for surveys and health research. Journal of Medical Internet Research, 4(2), E13. https://doi.org/10.2196/jmir.4.2.e13

Fletcher, B., Pine, K., \& Page, N. A. (2007). A new behavioural intervention for tackling obesity: Do Something Different. Agro Food Industry Hi Tech.

Fogg, B. J. (2003). Persuasive Technology: Using Computers to Change What We Think and Do. Morgan Kauffman.

Fornell, C., \& Larcker, D. F. (1981). Evaluating Structural Equation Models with Unobservable Variables and Measurement Error. Journal of Marketing Research, 18(1), 39-50. https://doi.org/10.2307/3151312

Gefen, D., Rigdon, E. E., \& Straub, D. (2011). Editor's Comments: An Update and Extension to 
SEM Guidelines for Administrative and Social Science Research. MIS Quarterly, 35(2), iiixiv. https://doi.org/10.2307/23044042

Hair Jr, J. F., Hult, G. T. M., Ringle, C., \& Sarstedt, M. (2013). A primer on partial least squares structural equation modeling (PLS-SEM). Sage Publications.

Halttu, K., \& Oinas-Kukkonen, H. (2017). Persuading to Reflect: Role of Reflection and Insight in Persuasive Systems Design for Physical Health. Human-Computer Interaction, 32(5-6), 381-412. https://doi.org/10.1080/07370024.2017.1283227

Ho, C.-H. (2010). Continuance Intention of E-Learning Platform: Toward an Integrated Model. International Journal of Electronic Business Management, 8(3), 206-215.

Jessup Schneider, A. L., \& Nicholas Graham, T. C. (n.d.). Nudging and Shoving: Using in-game cues to guide player exertion in exergames. Entertainment Computing. https://doi.org/http://dx.doi.org/10.1016/j.entcom.2017.01.002

Kahneman, D., \& Tversky, A. (1979). Prospect Theory: An Analysis of Decision under Risk. Econometrica, 47(2), 263-291. https://doi.org/10.2307/1914185

Karppinen, P., Oinas-Kukkonen, H., Alahäivälä, T., Jokelainen, T., Keränen, A.-M., Salonurmi, T., \& Savolainen, M. (2016). Persuasive User Experiences of a Health Behavior Change Support System: a 12-month Study for Prevention of Metabolic Syndrome. International Journal of Medical Informatics. https://doi.org/http://dx.doi.org/10.1016/j.ijmedinf.2016.02.005

Kelders, S. M., Kok, R. N., Ossebaard, H. C., \& Van Gemert-Pijnen, J. E. W. C. (2012). Persuasive system design does matter: a systematic review of adherence to web-based interventions. Journal of Medical Internet Research, 14(6), e152. https://doi.org/10.2196/jmir.2104

Kock, N. (2015). Common Method Bias in PLS-SEM: A Full Collinearity Assessment Approach. Int. J. e-Collab., 11(4), 1-10. https://doi.org/10.4018/ijec.2015100101

Kock, N., \& Lynn, G. (2012). Lateral collinearity and misleading results in variance-based SEM: An illustration and recommendations.

Langrial, S., Lehto, T., Oinas-Kukkonen, H., Harjumaa, M., \& Karppinen, P. (2012). Native 
Mobile Applications For Personal Well-Being: A Persuasive Systems Design Evaluation. PACIS 2012 Proceedings.

Langrial, S., Oinas-Kukkonen, H., Lappalainen, P., \& Lappalainen, R. (2013). Rehearsing to control depressive symptoms through a behavior change support system. In CHI'13 Extended Abstracts on Human Factors in Computing Systems (pp. 385-390). ACM.

Lee, M. K., Kiesler, S., \& Forlizzi, J. (2011). Mining Behavioral Economics to Design Persuasive Technology for Healthy Choices. In Proceedings of the SIGCHI Conference on Human Factors in Computing Systems (pp. 325-334). New York, NY, USA: ACM. https://doi.org/10.1145/1978942.1978989

Lehto, T., \& Oinas-Kukkonen, H. (2011). Persuasive features in web-based alcohol and smoking interventions: a systematic review of the literature. Journal of Medical Internet Research, 13(3), e46. https://doi.org/10.2196/jmir.1559

Lehto, T., \& Oinas-Kukkonen, H. (2015). Explaining and predicting perceived effectiveness and use continuance intention of a behaviour change support system for weight loss. Behaviour \& Information Technology, 34(2), 176-189. https://doi.org/10.1080/0144929X.2013.866162

Lehto, T., Oinas-Kukkonen, H., Pätiälä, T., \& Saarelma, O. (2012). Consumers’ Perceptions of a Virtual Health Check: An Empirical Investigation. ECIS 2012 Proceedings.

Lockton, D. (2012). Persuasive technology and digital design for behaviour change. Available at SSRN 2125957.

Markus, M. L., \& Tanis, C. (2000). The enterprise systems experience-from adoption to success. Framing the Domains of IT Research: Glimpsing the Future through the Past, 173, 173207.

Mogler, B. K., Shu, S. B., Fox, C. R., Goldstein, N. J., Victor, R. G., Escarce, J. J., \& Shapiro, M. F. (2013). Using Insights From Behavioral Economics and Social Psychology to Help Patients Manage Chronic Diseases. Journal of General Internal Medicine, 28(5), 711-718. https://doi.org/10.1007/s11606-012-2261-8

Moraveji, N., Akasaka, R., Pea, R., \& Fogg, B. J. (2011). The Role of Commitment Devices and Self-shaping in Persuasive Technology. In CHI '11 Extended Abstracts on Human Factors 
in Computing Systems (pp. 1591-1596). New York, NY, USA: ACM.

https://doi.org/10.1145/1979742.1979813

Munson, S. A., Krupka, E., Richardson, C., \& Resnick, P. (2015). Effects of Public Commitments and Accountability in a Technology-Supported Physical Activity Intervention. In Proceedings of the 33rd Annual ACM Conference on Human Factors in Computing Systems (pp. 1135-1144). New York, NY, USA: ACM. https://doi.org/10.1145/2702123.2702524

Nass, C., \& Moon, Y. (2000). Machines and Mindlessness: Social Responses to Computers. Journal of Social Issues, 56(1), 81-103. https://doi.org/10.1111/0022-4537.00153

Oinas-Kukkonen, H. (2013). A foundation for the study of behavior change support systems. Personal and Ubiquitous Computing, 17(6), 1223-1235. https://doi.org/10.1007/s00779012-0591-5

Oinas-Kukkonen, H., \& Harjumaa, M. (2009). Persuasive systems design: Key issues, process model, and system features. Communications of the Association for Information Systems, 24(1), 28.

Orji, R. O., Vassileva, J., \& Mandryk, R. L. (2013). Modeling Gender Differences in Healthy Eating Determinants for Persuasive Intervention Design BT - Persuasive Technology: 8th International Conference, PERSUASIVE 2013, Sydney, NSW, Australia, April 3-5, 2013. Proceedings. In S. Berkovsky \& J. Freyne (Eds.) (pp. 161-173). Berlin, Heidelberg: Springer Berlin Heidelberg. https://doi.org/10.1007/978-3-642-37157-8_20

Podsakoff, P. M., MacKenzie, S. B., Lee, J.-Y., \& Podsakoff, N. P. (2003). Common method biases in behavioral research: a critical review of the literature and recommended remedies. Journal of Applied Psychology, 88(5), 879-903.

Reeves, D. (2011). How To Do What You Want: Akrasia and Self-Binding. Retrieved 10 February 2016, from http://blog.beeminder.com/akrasia/

Ringle, C. M., Wende, S., \& Becker. (2015). SmartPLS 3. Boenningstedt: SmartPLS GmbH. Retrieved from https://www.smartpls.com/

Ritterband, L. M., Thorndike, F. P., Cox, D. J., Kovatchev, B. P., \& Gonder-Frederick, L. A. (2009). A behavior change model for internet interventions. Annals of Behavioral 
Medicine: A Publication of the Society of Behavioral Medicine, 38(1), 18-27.

https://doi.org/10.1007/s12160-009-9133-4

Rogers, T., Milkman, K. L., \& Volpp, K. G. (2014). Commitment devices: using initiatives to change behavior. JAMA, 311(20), 2065-2066.

Ryan, R. M., \& Deci, E. L. (2000). Intrinsic and Extrinsic Motivations: Classic Definitions and New Directions. Contemporary Educational Psychology, 25(1), 54-67. https://doi.org/http://dx.doi.org/10.1006/ceps.1999.1020

Schneider, H., Moser, K., Butz, A., \& Alt, F. (2016). Understanding the Mechanics of Persuasive System Design: A Mixed-Method Theory-driven Analysis of Freeletics. In Proceedings of the 2016 CHI Conference on Human Factors in Computing Systems (pp. 309-320). New York, NY, USA: ACM. https://doi.org/10.1145/2858036.2858290

Sørebø, Ø., Halvari, H., Gulli, V. F., \& Kristiansen, R. (2009). The role of self-determination theory in explaining teachers' motivation to continue to use e-learning technology. Computers \& Education, 53(4), 1177-1187.

https://doi.org/http://dx.doi.org/10.1016/j.compedu.2009.06.001

Stibe, A., \& Oinas-Kukkonen, H. (2014). Using Social Influence for Motivating Customers to Generate and Share Feedback. In Persuasive Technology (pp. 224-235). Springer International Publishing.

Williams, G. C., Freedman, Z. R., \& Deci, E. L. (1998). Supporting Autonomy to Motivate Patients With Diabetes for Glucose Control. Diabetes Care, 21(10), 1644 LP-1651.

Wood, W. (2000). Attitude Change: Persuasion and Social Influence - Annual Review of Psychology, 51(1):539.

Appendix 1: Measurement Instrument

\begin{tabular}{|l|l|l|}
\hline Constructs & Indicators & Loadings \\
\hline Dialogue Support & The system rewards me & 0.785 \\
\cline { 2 - 3 } Lehto et. al, (2012) & The system provides me with appropriate feedback & 0.751 \\
\hline
\end{tabular}




\begin{tabular}{|c|c|c|}
\hline \multirow[t]{2}{*}{$\begin{array}{l}\text { Lehto \& Oinas- } \\
\text { Kukkonen (2015) }\end{array}$} & $\begin{array}{l}\text { The system provides me with reminders for } \\
\text { reaching my goals* }\end{array}$ & 0.525 \\
\hline & The system encourages me & 0.784 \\
\hline \multirow{4}{*}{$\begin{array}{l}\text { Primary Task support } \\
\text { Lehto et. al, (2012) } \\
\text { Lehto \& Oinas- } \\
\text { Kukkonen (2015) }\end{array}$} & $\begin{array}{l}\text { They system makes it easier for me to reach my } \\
\text { goals }\end{array}$ & 0.839 \\
\hline & The system helps me gradually reach my goals & 0.877 \\
\hline & The system helps me keep track of my progress & 0.608 \\
\hline & The system offers me personalized content* & 0.450 \\
\hline \multirow{2}{*}{$\begin{array}{l}\text { Perceived Credibility } \\
\text { Lehto et. al, (2012) }\end{array}$} & The system provides trustworthy content & 0.922 \\
\hline & The system provides believable content & 0.937 \\
\hline \multirow{2}{*}{$\begin{array}{l}\text { Lehto \& Oinas- } \\
\text { Kukkonen (2015) }\end{array}$} & The system provides accurate content & 0.934 \\
\hline & The system provides professional information & 0.812 \\
\hline \multirow{3}{*}{$\begin{array}{l}\text { Social Support } \\
\text { Stibe \& Oinas- } \\
\text { Kukkonen (2014) } \\
\text { One self-developed }\end{array}$} & The system enables me to share with others & 0.768 \\
\hline & The system enables me to learn from others & 0.909 \\
\hline & $\begin{array}{l}\text { The system enables someone (chosen by me) to } \\
\text { check on my commitments }\end{array}$ & 0.750 \\
\hline \multirow{4}{*}{$\begin{array}{l}\text { Perceived } \\
\text { Competence } \\
\text { Deci \& Ryan (2000) } \\
\text { Williams et al. (1998) } \\
\text { Sørebø et al. (2009) }\end{array}$} & $\begin{array}{l}\text { By using the system, I feel confident in my ability } \\
\text { to achieve my goal. }\end{array}$ & 0.842 \\
\hline & $\begin{array}{l}\text { By using the system, I am capable of doing what it } \\
\text { takes to achieve my goal. }\end{array}$ & 0.900 \\
\hline & By using the system, I am able to achieve my goal. & 0.811 \\
\hline & $\begin{array}{l}\text { By using the system, I feel able to meet the } \\
\text { challenge of fulfilling my goal. }\end{array}$ & 0.878 \\
\hline
\end{tabular}




\begin{tabular}{|l|l|l|}
\hline \multirow{2}{*}{$\begin{array}{l}\text { Continuance } \\
\text { Intention }\end{array}$} & I intend to continue using the system & 0.936 \\
\cline { 2 - 3 } Bhattacherjee (2001) & I will be using the system in the future & 0.934 \\
\cline { 2 - 3 } & I am considering discontinuing using the system & 0.839 \\
\cline { 2 - 3 } & I am not going to use the system from now on & 0.778 \\
\hline
\end{tabular}

*: removed items

\section{Appendix 2: Description of the System}

As described in the study context, Beeminder (https://www.beeminder.com) is a Web-based information system for tracking different quantifiable goals. The system is for individuals who would either like to develop a new habit or stop undesired habits. The main goal typs tracked include Fitness and Training (e.g., biking a certain number of miles per month or year), Health (e.g., floss three times a week), Productivity (e.g., reduce time spent on Facebook, write for 30 minutes every night before bed), Finance (e.g., reduce ATM withdrawals to $€ 100 /$ month) and Learning (e.g., learn a new program language for 30 minutes each day). Registering to the system is free and registration comes with access to additional services such as ability to set up and track multiple goals, connect to different services, set up notification and reminder settings etc. One can also login to the system using other social web systems such as Facebook, twitter, and GitHub. 


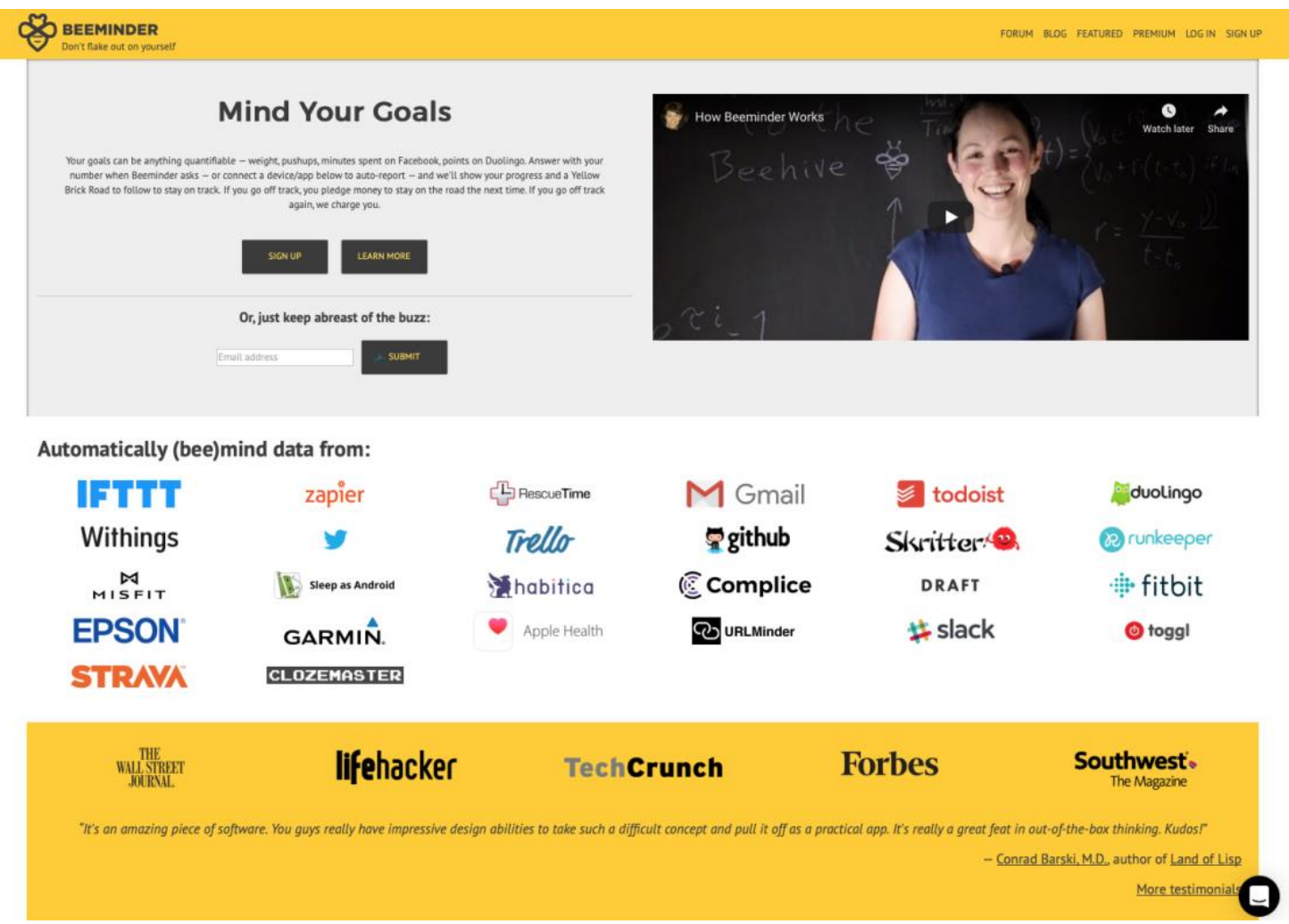

Figure A1. Screenshot of the system

\section{Mapping the system to the research model's constructs}

Primary task support

- Simplified goal-setting process and breaking it into small steps

- Tracking and plotting of progress

- Those on premium plans have own programs with personalised recommendations

\section{Dialogue support}

- Email/SMS reminders which are more frequent the closer one is to derailing

- A periodic e-mail newsletter about the system and other related topics 


\section{Credibility support}

- Contact information and short bios for the owners of the system are provided.

- Links are provided to testimonials and other third-party endorsements.

- The Website is professionally designed, does not have errors and sources to the information provided are provided (expertise and verifiability).

- There are no advertisements which can reduce the credibility.

\section{Social support}

- Discussion forums with ideas on goals to track and success/failure stories.

- Possibility to compare progress with others

- Possibility to give contact information for people to be contacted when you derail on a goal. 